\title{
Only vaccinations cannot reduce mortality and stop the COVID-19 pandemic because of manifold environmental and socioeconomic factors driving diffusion
}

\section{Mario Coccia ( $\nabla$ mario.coccia@cnr.it)}

\section{Research Article}

Keywords: COVID-19 pandemic, SARS-CoV-2, Vaccination program, Vaccines, Excess mortality, COVID/19 deaths, SARS-CoV-2 Variants, Mutations, Mechanical ventilation, COVID-19 ventilators, Policy responses, Management of COVID-19 pandemic, Policymaking, Public health, Pandemic policies, Socioeconomic factors, Environmental factors

Posted Date: January 31st, 2022

DOI: https://doi.org/10.21203/rs.3.rs-1312175/v1

License: (c) (i) This work is licensed under a Creative Commons Attribution 4.0 International License. Read Full License 


\section{Abstract}

One of the fundamental problems in COVID-19 pandemic crisis is whether vaccinations are a sufficient strategy to reduce mortality and mitigate negative effects of this novel infectious disease in society. This study confronts the problem here by developing an analysis of the relation between people fully vaccinated and mortality between countries to clarify sources and effects of COVID-19 pandemic in society. Methodology applies correlation and regression analyses based on global data of more than 150 countries. Findings reveal a strong positive correlation between share of people fully vaccinated and COVID-19 mortality in January $2022(r=.65, p$-value <.01). Multiple analysis of regression shows that a $1 \%$ higher share of people fully vaccinated, increases the expected deaths per 100 000 people by $0.7 \%$ ( $p$-value $<0.001)$, controlling GDP per capita between countries. These results seem to suggest that COVID-19 vaccinations are not a sufficient strategy to reduce the negative impact of the new infectious disease in society, because socioeconomic and environmental factors, mutations of the novel coronavirus and technological aspects of countries (e.g., equipment of non-invasive ventilators in countries) affect the spread and mortality of this pandemic between countries. Overall, then, a pandemic policy only based on vaccinations cannot cope with the eradication of COVID-19 pandemic because manifold factors drive the transmission dynamics of COVID-19 and generate a lot of negative impacts in economic systems, though high levels of vaccinations in some countries.

\section{Introduction And Goal Of Investigation}

We are still in the throes in 2022 of negative socioeconomic effects of the pandemic of Coronavirus Disease 2019 (COVID-19), an infectious illness generated by (novel) mutant viral agent of the Severe Acute Respiratory Syndrome Coronavirus 2/SARS-CoV-2 (Bontempi et al., 2021; Bontempi and Coccia, 2021; Coccia, 2020, 2020a, 2020b, 2021; Johns Hopkins Center for System Science and Engineering, 2022; Vinceti et al., 2021)[1]. Initially, in 2020, countries apply non-pharmaceutical interventions (e.g., lockdown and quarantine) to cope with COVID-19 pandemic crisis; a later time, in 2021 and 2022, the most applied health policy worldwide is the administration of new types of vaccines based on viral vector, protein subunit and nucleic acid-RNA (Abbasi, 2020; Coccia, 2021g, 2022a, 2022b, 2022c; Mayo Clinic, 2021). The vaccination plans have the potential goal to reduce the diffusion of COVID-19, to relax non-pharmaceutical measures and maintain low basic reproduction number, but an important problem is whether these novel types of vaccines are really effective to reduce high numbers of COVID-19 related infected individuals and deaths between countries to control and/or eradicate the pandemic diffusion and to reduce negative effects in society (Aldila et al., 2021; Coccia, 2021a; Prieto Cruriel, et al. 2021; Saadi et al., 2021). Akamatsu et al. (2021) argue the vital role of governments to implement an efficient campaign of vaccination to substantially reduce infections in society, and avoid the collapse of healthcare system (cf., Coccia, 2021b, 2021c, 2022a). Shattock et al. (2021) argue that a rapid vaccination rollout can allow the sooner relaxation of non-pharmaceutical interventions, but emerging viral variants of SARS-CoV-2 create new scenarios and problems for epidemic control (Fontanet et al., 2021; Papanikolaou et al., 2021). Shattock et al. (2021) also find that a gradual phased relaxation can substantially reduce population-level morbidity and mortality and that faster vaccination campaign can offset the size of pandemic wave, allowing more flexibility for non-pharmaceutical control measures to be relaxed sooner. Aldila et al. (2021) maintain that higher levels of vaccination rate can eradicate COVID-19 in population by approaching herd immunity to protect vulnerable individuals (cf., Anderson et al., 2020; de Vlas and Coffeng, 2021; Randolph and Barreiro, 2020). However, Aschwanden $(2020,2021)$ raised many doubts about the achievement of hear immunity, which is a "false promise" because of manifold factors affecting transmission dynamics of COVID-19 (cf., Moore et al., 2021). Seligman et al. (2021) analyze the COVID-19 pandemic in the United States and show that social determinants can affect COVID-19 mortality at the individual level. Results of demographics of deaths reveal a mean age of 71.6 years, $45.9 \%$ female, and $45.1 \%$ non-Hispanic white. They found that disproportionate deaths occurred among individuals with nonwhite race/ethnicity, individuals with income below the median, individuals with less than a high school level of education, and veterans 
(cf., Davies et al., 2021; Wolf et al., 2021). In general, substantial inequalities in COVID-19 mortality are due to racial/ethnic minorities and poor people having less education. Garber (2021) for the US case study maintains that mortality from COVID-19 rises steeply with advancing age, in a pattern that largely parallels overall mortality. Age specific mortality rates increased in the US more for groups that already experienced greater mortality, such as nonHispanic Black people, as reflected in projections of life expectancy at birth. Ackley et al. (2022), investigating the impact of the COVID-19 pandemic in the US, show that a significant percentage of excess deaths associated with the pandemic were not directly assigned to COVID-19. Across the U.S.A., the estimates of model indicate about 438,386 excess deaths occurred in 2020, among which 87.5\% were assigned to COVID-19. Some regions of Mideast, Great Lakes, New England, etc. had the most excess deaths in large central metropolitan areas, whereas other regions (Southwest, Southeast, Rocky Mountains, Great Plains, etc. ) reported the highest excess mortality in non-metropolitan areas. Stokes et al (2021) found that direct COVID-19 death counts in the US in 2020 are substantially underestimated total excess mortality attributable to COVID-19. Racial and socioeconomic inequities in COVID-19 mortality also increased when excess deaths not assigned to COVID-19 were considered (cf., Stokes et al., 2021a). Sanmarchi et al. (2021) argue that many countries experienced an increase in mortality during 2020. Several Latin American and East European countries exhibit a large gap between Excess Mortality (EM) and COVID-19 Confirmed Mortality (CCM), such as Mexico; other countries showed a moderate EM beyond CCM (e.g., Greece). Countries with negative EM also had very low CCM and were mainly located in East Asia. Islam et al. (2021) point out that about one million excess deaths occurred in 2020 in many high-income countries. Age standardized excess death rates were higher in men than women in almost all countries. Excess deaths substantially exceeded reported deaths from COVID-19 in many countries, indicating that determining the full impact of the pandemic on mortality requires assessment of excess deaths. Kiang et al. (2020) argue that the true number of deaths resulting from COVID-19, both directly and indirectly, is likely to be much higher, and correct analysis and evaluation of excess mortality are critical goals to understanding this pandemic and its effect on human life and overall society. In general, these studies clearly show that the mortality of COVID-19 pandemic is a critical indicator associated with manifold factors (Barnard et al., 2021; Garber, 2021; Islam et al., 2021; Stokes et al., 2021, 2021a; Woolf et al., 2021). In this context, this study develops a statistical analysis to explain some relations between the level of vaccinations and mortality rate of COVID-19 between countries to clarify complex factors determining pandemic diffusion and negative impact in society. These results can support the design of best practices of crisis management to cope with current and future pandemic crisis similar to COVID-19 (cf., Coccia, 2019g). This study is part of a large research project to explain drivers of transmission dynamics of COVID-19 and design effective policy responses to cope with and/or to prevent pandemic threats in society (Coccia, 2020, 2020a, 2020l, 2021, 2022a).

[1] Cf. also Coccia, 2020c, 2021a, 2021d, 2021e, 2021f, 2021g, 2022.

\section{Study Design}

\subsection{Sample}

The total sample of this study is $N=151$ countries worldwide. For some statistical analyses based on different confounding factors, the sample can be lower for missing data of some variables.

\subsection{Measures for statistical analyses}

- Vaccination is measured by percent share of people fully vaccinated against COVID-19 over 11 January 2022. Data refer mainly to January 2022 but some countries, because of difficulty in the gather and transmission of information, can have data of December 2021. Of course, this small temporal gap of some countries does not 
affect the statistical analyses based on a large sample $>100$ units. The data here consider all types of COVID-19 vaccines used in different countries, i.e., vaccines by Johnson \& Johnson, Oxford/AstraZeneca, Pfizer/BioNTech, Sinopharm/Beijing, Sinovac, Sputnik V and Moderna (Ritchie et al., 2020). Of course, every country has been using a different combination of these COVID-19 vaccines to protect the population. Source: Our World in Data (2022).

- Gross Domestic Product (GDP) per capita in 2020. GDP per capita (constant 2010 US\$). GDP per capita is gross domestic product divided by midyear population. GDP is the sum of gross value added by all resident producers in the economy plus any product taxes and minus any subsidies not included in the value of products. It is calculated without making deductions for depreciation of fabricated assets or for depletion and degradation of natural resources. Data are in constant 2010 U.S. dollars. Source: The World Bank (2022).

- Population Total 2020. Total population is based on the de facto definition of population, which counts all residents regardless of legal status or citizenship. The values are midyear estimates. Source: The World Bank (2022a).

- COVID-19 Deaths. Total number of deaths in January 2022. It indicates the severity of this novel infectious disease in socioeconomic systems. This study also calculates the mortality rate per 100000 people for a comparative analysis between countries. Source of data: Johns Hopkins Center for System Science and Engineering (2022).

\subsection{Model and data analysis procedure}

Firstly, data are analyzed with descriptive statistics given by arithmetic mean and standard error of the mean. The normality of distribution of variables under study is checked with skewness and kurtosis coefficients and if distribution of variables is not normal, they are transformed in logarithmic scale for having normality and performing appropriate parametric analyses (Coccia, 2018).

This study focuses on the following ratio of COVID-19 deaths calculated for all countries:

\section{Mortality rate per 100000 people $=\left(\frac{\text { Total number of deaths from COVID-19 at January } 2022}{\text { Total population in } 2020}\right) \times 100000$}

Secondly, variables under study are analyzed with the bivariate Pearson Correlation that produces a sample correlation coefficient, $r$, which measures the strength and direction of linear relationships between pairs of continuous variables, given by share of people fully vaccinated against COVID-19 and mortality rate (deaths / population ' 100 000) between countries. This study also calculates the partial correlation that indicates the strength and direction of a linear relationship between continuous variables just mentioned whilst controlling for the effect of GDP per capita.

The strength of correlation can be assessed by these general guidelines:

$0.1<|\mathrm{r}|<0.3 \ldots$ small / weak correlation

$0.3<|\mathrm{r}|<0.5 \ldots$ medium / moderate correlation

$0.5<|r| \ldots \ldots . .$. large / strong correlation

Thirdly, the analysis of multiple regression is applied to predict the value of mortality rate (dependent or response variable) on the value of two explanatory variables: share of people fully vaccinated against COVID-19 and GDP per 
capita (independent variables or predictors).

The specification of $\log$-log model is given by:

$$
\log y_{i, t}=\alpha_{0}+\beta_{1} \log \mathrm{x}_{\mathrm{i}, \mathrm{t}}+\beta_{2} \log \mathrm{z}_{\mathrm{i}, \mathrm{t}-1, \mathrm{~W}}^{\mathrm{m}}+u_{i, t}
$$

where:

1. $y_{i, t-}=$ Mortality rate of COVID-19 in January 2022.

2. $x_{i, t}=$ Share $\%$ of people fully vaccinated against COVID-19 in January 2022

3. $z_{i, t-1}=$ GDP per capita in 2020

4. $u_{i, t}=$ Error term

country $i=1, \ldots, n ; \quad t=$ time

Results of regression analysis are the $\mathrm{R}^{2}$ and the standard error of the estimate, which determine how well regression model fits the data. $R^{2}$ value (also called the coefficient of determination) is the proportion of variance in the dependent variable that can be explained by independent variables. The F-ratio in the ANOVA table tests whether the overall regression model is a good fit for the data. Unstandardized coefficients of partial regression indicate how much the dependent variable varies with an independent variable when the other independent variable is held constant and finally the statistical significance of each of the independent variables with $t$-test. Statistical analyses are performed with the Statistics Software SPSSâ version 26.

\section{Results}

Table 1. Descriptive statistics

\begin{tabular}{lccccc} 
Variables & N & Mean & $\begin{array}{l}\text { Std. Error of } \\
\text { Mean }\end{array}$ & Skewness & Kurtosis \\
\hline GDPPC 2020, GDP per capita \$ & 151 & $14,457.69$ & $1,716.74$ & 2.68 & 9.64 \\
\hline $\begin{array}{l}\text { MOR2022, Mortality rate per 100 000 people } \\
\text { (number) }\end{array}$ & 151 & 111.43 & 9.75 & 1.33 & 1.69 \\
\hline $\begin{array}{l}\text { VAC2022, Share \% of people fully vaccinated } \\
\text { Log GDPPC2020 }\end{array}$ & 144 & 44.14 & 2.26 & -0.13 & -1.29 \\
\hline LogMOR2022 & 149 & 8.68 & 0.12 & 0.07 & -0.90 \\
\hline LogVAC2022 & 151 & 3.82 & 0.13 & -0.58 & -0.68 \\
\hline
\end{tabular}

Table 1 shows descriptive statistics and that variables with logarithmic transformation have a normal distribution (coefficients of skewness and kurtosis have values in the correct range) to perform appropriate and robust parametric analyses.

Table 2. Bivariate correlation 


\begin{tabular}{lll} 
Pearson Correlation & LogVAC2022 & LogMOR2022 \\
\hline LogVAC2022 & 1 & $.646^{\star \star}$ \\
\hline N & 144 & 144
\end{tabular}

Note: MOR2022, Mortality rate per 100000 people in 2022, VAC2022, Share \% of people fully vaccinated in 2022.

** Correlation is significant at the 0.01 level (1-tailed).

The bivariate Pearson Correlation produces, in the sample of $N=144$ countries, a positive coefficient $r=.65$ ( $p$ value<0.01), which indicates a strong correlation between mortality rate per 100000 people and share \% of people fully vaccinated. This finding is confirmed in table 3 with the partial correlation that indicates the moderate linear relationship between continuous variables just mentioned, controlling for the effect of GDP per capita $\left(r_{\text {partial }}=.44, p\right.$ value=.001).

Table 3. Partial correlation

\begin{tabular}{clll} 
Control variable: GDPPC2020 & Partial Correlation & LogVAC2022 & LogMOR2022 \\
& LogVAC2022 & 1 & $.443^{\star \star \star}$ \\
\hline N & 135 & 135
\end{tabular}

Note: GDPPC 2020, GDP per capita; MOR2022, Mortality rate per 100000 people in 2022; VAC2022, Share \% of people fully vaccinated in 2022 .

*** Correlation is significant at the 0.001 level (1-tailed).

Table 4. Regression analyses of mortality rate in 2022 on people fully vaccinated in 2022 (and GDP per capita 2020), $\log$-log model [1]

\begin{tabular}{lll} 
& Simple Regression & Multiple regression \\
\hline Constant a & $0.754^{\star}$ & -0.542 \\
(St. Err) & $(0.325)$ & $(0.665)$ \\
\hline VAC2022, Coefficient $b_{1}$ & $0.917^{\star \star \star}$ & $0.713^{\star \star \star}$ \\
(St. Err.) & $(0.091)$ & $(0.132)$ \\
\hline GDPPC2020, Coefficient $b_{2}$ & - & $0.228^{\star}$ \\
(St. Err.) & & $(0.103)$ \\
\hline$R^{2}$ & .42 & .43 \\
$($ St. Err. of Estimate) & $(1.23)$ & $(1.22)$ \\
\hline$F$ & $101.70^{\star \star \star}$ & $52.80^{\star \star *}$
\end{tabular}

Note: Dependent (response) variable is: MOR2022, Mortality rate per 100000 people in 2022; Explanatory variables are: VAC2022, Share (\%) of people fully vaccinated against COVID-19 in 2022 and GDPPC2020, Gross Domestic Product per capita in 2020. Significance: ***p-value $<0.001 ; p$-value $<0.05$ 
Table 4 shows results of simple and multiple regression. Since results are rather similar, we describe estimated multivariate relationship based on Eq. [1] with two explanatory variables (i.e., Share \% of people fully vaccinated against COVID-19 in 2022 and Gross Domestic Product per capita in 2020). The partial coefficient of regression $b_{1}$ of the model indicates that a $1 \%$ higher share of people fully vaccinated (controlling GDP per capita), increases the expected mortality rate of COVID-19 per 100000 people by $0.7 \%$ ( $p$-value $<0.001$ ), whereas the partial coefficient of regression $b_{2}$ of the model indicates that a $1 \%$ higher level of GDP per capita (controlling share $\%$ of people fully vaccinated), increases the expected mortality rate of COVID-19 per 100000 people by $0.2 \%$ ( $p$-value $<0.05)$. $F$ - test (the ratio of the variance explained by the model to the unexplained variance) is significant at $1 \%$ o (i.e., $p$-value $<0.001$ ), such that overall regression model is a good fit for the data. $\mathrm{R}^{2}$ of the model of multiple regression indicates that about $53 \%$ of the variation in mortality rate of COVID-19 can be attributed (linearly) to share (\%) of people fully vaccinated against COVID-19 in 2022 and Gross Domestic Product per capita in 2020. Figure 1 shows regression line of COVID-19 deaths per 100000 people on share of people vaccinated against COVID-19 (\%) based on log-log model.

Hence, these critical findings suggest that increasing the share of people vaccinated against COVID-19 is a necessary but not sufficient condition to mitigate the negative impact of COVID-19 in society in terms of reduction of mortality. In fact, the diffusion of the mutant novel coronavirus has complex aspects, and the increasing level of vaccinations seems not to a health policy enough to control the pandemic and reduce mortality because the transmission dynamics is driven by manifold environmental and socioeconomic factors that are discussed in the following section.

\section{Discussions}

The critical findings of this study are a strong correlation between mortality rate per 100000 people and share $\%$ of people fully vaccinated against COVID-19 (also controlling for the effect of GDP per capita). This result can be explained with the fact that COVID-19 vaccinations are a necessary but not sufficient strategy to reduce the negative impact of the novel coronavirus in society, because there are manifold factors that support the diffusion and mortality of this pandemic, also in countries having a high level of fully vaccinated people.

Determinants of the pervasive diffusion of COVID-19 in society, which vaccinations cannot stop, are: new variants, high air pollution and density of people in cities, intensive commercial activities of countries, low investments in healthcare sectors and little new technology (such as non-invasive medical ventilation), etc.[2] (Figure 2).

\section{- High level of air pollution}

Coccia $(2020,2021)$ finds out, based on a case study of Italy, that the number of infected people was higher in cities with >100 days per year exceeding limits set for $\mathrm{PM}_{10}$ or ozone and cities located in hinterland zones (i.e., away from the coast). In hinterland cities (mostly those bordering large urban conurbations) with a high number of days exceeding $\mathrm{PM}_{10}$ and ozone limits, coupled with low wind speed, the average number of infected people in April 2020 more than doubled that of more windy coastal cities in Italy that had also exceeded the air pollution limits. These findings provide valuable insight into geo-environmental factors that may accelerate the diffusion of COVID-19 and similar viral agents. Studies show that sustainable environment plays a vital role for reducing COVID-19 related infected individuals and deaths; in particular, a low rate of fatality is associated with a low level of air pollution (cf., Coccia, 2020a, 2020b, 2020c). In fact, average population exposed to levels exceeding WHO guideline value (\% of total) is $72 \%$ in countries with a lower level of fatality rate, whereas in countries with a higher incidence of mortality of the COVID-19 is almost 98\%. Coccia (2020a; 2022b, 2022c) maintains that a proactive strategy to cope with future epidemics should concentrate on reducing levels of air pollution in hinterland and polluted cities. Copat et al. (2020), considering different studies about the relation between air pollution and the spread of COVID-19, suggest that

Page $7 / 20$ 
$\mathrm{PM}_{2.5}$ and $\mathrm{NO}_{2}$ can support the spread and lethality of COVID-19, but additional analyses are needed to confirm this relation concerning transmission dynamics and negative effects of the SARS-CoV-2 in society (cf., Coccia, 2021).

\section{- Climate factors: low wind speed and temperature, high humidity}

Studies suggest that the concentration of atmospheric pollutants is a main driver of the spread of SARS-CoV-2 (Coccia, 2020a), but a high wind speed sustains clean days from air pollution, reducing whenever possible the spread of COVID19 (cf., Coccia, 2020b, 2021, 2021a, 2021f; Caliskan et al., 2020). To put it differently, a low wind speed in cities prevents the dispersion of air pollutants that can include bacteria and viruses, such as SARS-CoV-2, and can increase the incidence of COVID-19, such as in some European regions (Coccia, 2020a, 2020b, 2020c; 2021). Rosario et al. (2020, p. 4) suggest that wind improves the circulation of air and increases the exposure of the novel coronavirus to the solar radiation effects, a factor having a negative correlation in the diffusion of COVID-19. Nicastro et al. (2021) also analyze the spatial aspects of SARS-CoV-2 in response to UV light and solar irradiation measurements on Earth. The results of study show that UV-B/A photons have a powerful virucidal effect on the single-stranded RNA virus of the COVID-19. Moreover, the solar radiation thar reaches temperate regions of the Earth at noon during summers, it is a sufficient condition to inactivate $63 \%$ of virions in open-space concentrations in less than 2 minutes.

\section{- High density of cities and intensive commercial activities}

Coccia (2020a, 2020b) showed, with a case study of Italy, that average number of infected individuals increases with average density of people/ $\mathrm{km}^{2}$. In fact, the density of population per $\mathrm{km}^{2}$ is an important factor for transmission dynamics of infectious diseases and studies confirm that high population density increases the probability of interpersonal contacts and viral transmission of COVID-19 in cities (Coccia, 2020a, 2021). Moreover, Bontempi and Coccia (2021) and Bontempi et al. (2021) find out that an intensive commercial activity, measured with the level of import and export, can be a main predictor of the diffusion of COVID-19 in society. In particular, the study suggests that total import and export of Italian provinces has a high association with confirmed cases over time (average $r>.78, p$ value $<.001)$. Another study based on three large countries in Europe (Italy, France, and Spain) suggests the positive association between trade and pandemic diffusion. In general, international trade data is supposed to be a complex parameter of the transmission dynamics of the COVID-19 that includes many factors related to economic, demographic, environmental, and climate aspects.

\section{- New SARS-CoV-2 variants of concern}

The novel coronavirus in environment and human ecosystem constantly changes through mutations. A new mutation generates a variant of the original virus of SARS-CoV-2. Fontanet et al. (2021) argue that in December 2020, an unexpected rise in reported COVID-19 cases was attributed to the emergence of new SARS-CoV-2 variants (Alfa, B.1.1.7) in the UK and (Beta, B.1.351) in South Africa. Both variants had a mutation in the receptor-binding domain of the spike protein that is reported to increase transmission, ranging between $40 \%$ and $70 \%$. Davies et al. (2021) show that Alpha variant (B.1.1.7) of SARS-CoV-2 is more transmissible than pre-existing variants. This study estimates that the hazard of deaths associated with B.1.1.7 is $61 \%$ higher than pre-existing variants. In short, analysis suggests that B.1.1.7 is not only more transmissible than previous SARS-CoV-2 variants but may also cause more severe illness. Other two variants of the novel coronavirus (SARS-CoV-2) that cause coronavirus disease 2019 (COVID-19) and subsequent health and socioeconomic problems are (Mayo Clinic, 2022):

- Delta (B.1.617.2). This variant is nearly twice as contagious as earlier variants and might cause more severe illness. The greatest risk of transmission is among unvaccinated people. People who are fully vaccinated can get vaccine breakthrough infections and spread the virus to others. However, it appears that vaccinated people spread 
COVID-19 for a shorter period than do unvaccinated people. While research suggests that COVID-19 vaccines are slightly less effective against the delta variant.

- Omicron (B.1.1.529). This variant might spread more easily than other variants, including delta. But it's not yet clear if omicron causes more severe disease. It's expected that people who are fully vaccinated likely can get breakthrough infections and spread the virus to others. However, the COVID-19 vaccines are expected to be effective at preventing severe illness. This variant also reduces the effectiveness of some monoclonal antibody treatments.

The alpha, gamma and beta variants of SARS-CoV-2 continue to be monitored but are spreading at much lower levels. The mu variant is also being monitored. Of course, these variants of the novel coronavirus change the transmissions dynamics and negative effects in society.

\section{- Health investments and new technology of medical ventilators}

Coccia (2021e) reveals that countries with lower fatality rates have a high average level of health expenditure given by $7.6 \%$ of GDP and average government health expenditure per capita of about $\$ 2,300$, whereas countries with higher fatality rates of COVID-19 have an average health expenditure of roughly $6 \%$ of GDP and very low government health expenditure per capita (a mere average value of about $\$ 243$ per inhabitants) that indicates a weak healthcare sector to cope with pandemics and also other diseases in society. In the context of COVID-19, a main technology to cope with a serious illness of people admitted in Intensive Care Units (ICUs) is mechanical ventilator (it is an artificial breathing device that is used for patients who are not able to breathe naturally due to a critical illness, such as COVID-19). Some of the most used products include positive and negative mechanical ventilators that are utilized in ICUs, neonatal care centers and ambulances. These devices consist of a hollow tube that is inserted into the patient's trachea to create a stable airway. They also assist in maintaining adequate levels of oxygen and carbon dioxide in the body to relieve respiratory distress, reverse respiratory muscle fatigue and initiate lung healing (IMARC, 2022). However, invasive ventilation can create problems to lung and infection in case of prolonged utilization, such as to treat COVID-19 patients. Ventilator-associated lung injury, sometimes referred to as ventilator-induced lung injury, is damage to the alveolar and / or small airways related to mechanical ventilation. Possible mechanisms include alveolar over distension and shear forces created by repeated opening and collapsing of the alveoli, leading to the release of inflammatory mediators that result in increased alveolar permeability and fluid accumulation. New technology is more and more based on Non-Invasive Ventilation (NIV) that refers to the administration of ventilatory support without using an invasive artificial airway (endotracheal tube or tracheostomy tube). The use of NIV has markedly increased over the past two decades, and NIV has now become an integral tool in the management of both acute and chronic respiratory failure, in both the home setting and in the critical care unit. Non-invasive ventilation is a new technology that is generating a replacement for invasive ventilation, and its flexibility also allows it to be a valuable complement in patient management (Soo Hoo, 2020, 2010). New technology of NIV accurately measures patient's airway pressure, moreover the respiratory abdominal sensor and transducer allow patient-triggered pressure assists with breath rate monitoring. New technology of NIV allows an adequate humidification to maintain airway clearance, optimize ventilation and improve patient comfort (in fact, normal functions of the nose and air passages of the respiratory tract are to warm, moisten and filter the inhaled gases before they reach the lungs. In normal respiration, the nasal mucosa and upper airways provide $75 \%$ of the heat and moisture supplied to the smaller airways and alveoli. By the time air reaches the alveoli, the inspired gas warms to $37^{\circ} \mathrm{C}$ at $100 \%$ relative humidity). In short, benefits of NIV are due to both the patient and the facility using it, such as cost-effective, no need for sedation, comfortable for the patient, intubation and airway skills not required and time-efficient for facility. In the presence of pandemic crisis some countries, such as Germany had a high number of medical ventilators: about 30,000 in 2020 (Our World in Data, 2022a) and though a population of 83.24 million, COVID-19 deaths (117 318) are lower than for instance Argentina that has 120019 deaths 
with about 45 million of people (The World Bank, 2022a; Johns Hopkins Center for System Science and Engineering, 2022). Other scholars, such as Kapitsinis (2020), argue that investments in health sector are a critical public policy to mitigate mortality rate of COVID-19. Hence, countries should support healthcare investments in the expansion of hospital capacity and R\&D investments in new technology to develop effective vaccines, antivirals, innovative drugs and high-tech devices that can counteract future public health threats of new epidemics like COVID-19 (Ardito et al., 2021; Coccia, 2017c, 2017d, 2019f, 2020).

[2] For role of science, technology, research labs, leading firms and institutions for economic and social change see: Ardito et al., 2021; Coccia, 2003, 2005, 2005a; Coccia, 2008, 2013, 2014, 2015, 2016, 2107, 2017a, 2017b, 2017c, 2017d, 2017e, 2018a, 2018b, 2018c, 2018d, 2018e, 2018f, 2019, 2019a, 2019b, 2019c, 2019d, 2018e, 2019f; 2018g, 2019h, 2019i, Coccia, 2020d, 2020e, 2020f, 2020g, 2020h, 2020i; Coccia, 2021h, 2021i, 2020l; Coccia, 2022d; Coccia and Bellitto, 2018; Coccia and Benati, 2018; Coccia and Cadario, 2014; Coccia and Finardi, 2012, 2013; Coccia and Rolfo, 2000, 2008; Coccia and Watts, 2020; Pagliaro and Coccia, 2021; Pronti and Coccia, 2020.

\section{Conclusions}

Lau et al. (2021) argue that in the presence of a continuous global COVID-19 pandemic threat, the mortality rate is a main indicator to evaluate the real effects of COVID-19 in society (cf., Liu et al., 2021). In this context, one of the goals of nations to cope with COVID-19 pandemic crisis is to mitigate mortality and case fatality rate (cf., Coccia, 2020a, 2021e). Initially, in 2020, countries apply non-pharmaceutical interventions (e.g., lockdown) to cope with COVID-19 pandemic crisis; a later time, in 2021 and 2022, the most applied health policy worldwide is the administration of vaccinations on a vast population (Coccia, 2022b). Findings here reveal that the increase of vaccinated people (\%) against COVID-19 is not associated with a reduction of mortality of COVID-19 between countries because manifold factors can affect the complex dynamics of diffusion of COVID-19 pandemic in environment and society. Although this study has provided interesting results, that are of course tentative, it has several limitations. First, a limitation of the study is the lack of data about total vaccinations in manifold countries. Second, not all the possible confounding factors that affect the diffusion of vaccination and mortality of COVID-19 are taken into consideration and in future these factors deserve to be controlled for supporting results here. Third, the lack of integration of data with socioeconomic aspects of countries may influence the results of mortality, making comparative analyses a problematic approach (Angelopoulos et al., 2020; Coccia, 2018). Fourth, country-specific health investments may affect the vaccination, management of healthcare and mortality of people and have to be controlled in future development of this study. Finally, the estimated relationships in this study focus on variables in specific months (based on recent data available) but an extension of the period under study is needed to reinforce results here. Thus, the generalization of this results should be done with caution.

Future research should consider new data, when available, and when possible, to examine also other variables between countries to explain the interaction between vaccination, mortality and other socioeconomic factors between countries. Despite these limitations, results presented here suggest that the vaccination is a health policy not enough to reduce mortality of COVID-19, control and stop the pandemic diffusion and subsequent negative effects in society. Hence, there is need for much more detailed research in these topics and this study encourages further investigations to clarify complex factors driving pandemics in environment and ecosystems also considering the interaction between restrictions, vaccinations and general investments in healthcare. To conclude, different factors between countries that are not only parameters related to medicine but also to social, economic and innovation studies can explain the mortality of COVID-19 pandemic in society and should be accurately considered to control future negative impact of pandemic crisis on public health, economy and society. Hence, results here have to be reinforced with much more 
follow-up investigation concerning detailed research into the relations between negative effects of pandemic in society, health system, public health capacity and pandemic response of countries.

Overall, then, this study suggests that an effective strategy to reduce the negative impact (in terms of mortality) of future pandemic threats similar to COVID-19, it has to be based on high investments in health system and design of comprehensive health, social and economic policy responses of crisis management, not only vaccination-based approach, considering that complex environmental and socioeconomic factors guide transmission dynamics of COVID-19 and negative effects in society. To conclude, this study here suggests analyzing further socio-economic factors that may shape and support general health strategy, beyond vaccinations, to cope with future pandemic crises by creating appropriate ecosystems and socioeconomic systems of countries that improve public health and overall wellbeing of people.

\section{Declarations}

\section{Declaration of competing interest}

The author declares that he is the sole author of this manuscript, and he has no known competing financial interests or personal relationships that could influence the work reported in this paper.

This study has no funders.

\section{References}

Abbasi J. 2020. COVID-19 and mRNA Vaccines-First Large Test for a New Approach. JAMA, 324(12), 1125-1127. https://doi.org/10.1001/jama.2020.16866

Ackley, C.A., Lundberg, D.J., Ma, L., (...), Preston, S.H., Stokes, A.C. $\quad$ 2022. County-level estimates of excess mortality associated with COVID-19 in the United States, SSM - Population Health 17,101021

Akamatsu, T., Nagae, T., Osawa, M., Satsukawa, K., Sakai, T., Mizutani, D. 2021. Model-based analysis on social acceptability and feasibility of a focused protection strategy against the COVID-19 pandemic. Scientific reports, 11(1), 2003. https://doi.org/10.1038/s41598-021-81630-9

Aldila, D., Samiadji, B.M., Simorangkir, G.M., Khosnaw, S.H.A., Shahzad, M.2021. Impact of early detection and vaccination strategy in COVID-19 eradication program in Jakarta, Indonesia, BMC Research Notes, 14(1),132

Anderson, R. M., Vegvari, C., Truscott, J., Collyer, B. S. 2020. Challenges in creating herd immunity to SARS-CoV-2 infection by mass vaccination. Lancet (London, England), 396(10263), 1614-1616. https://doi.org/10.1016/S01406736(20)32318-7

Angelopoulos A. N., Pathak R., Varma R., Jordan M. I. 2020. On Identifying and Mitigating Bias in the Estimation of the COVID-19 Case Fatality Rate. Harvard Data Science Review. https://doi.org/10.1162/99608f92.f01ee285

Ardito L., Coccia M., Messeni Petruzzelli A. 2021. Technological exaptation and crisis management: Evidence from COVID-19 outbreaks. R\&D Management, vol. 51, n. 4, pp. 381-392. Special Issue: Providing solutions in emergencies: R\&D and innovation management during Covid-19 Part-2, https://doi.org/10.1111/radm.12455 
Aschwanden C. 2020. The false promise of herd immunity for COVID-19. Nature. Nov;587(7832):26-28. doi: $10.1038 / d 41586-020-02948-4$

Aschwanden C. 2021. Five reasons why COVID herd immunity is probably impossible. Nature, 591(7851), 520522. https://doi.org/10.1038/d41586-021-00728-2

Barnard, S., Chiavenna, C., Fox, S., Charlett, A., Waller, Z., Andrews, N., Goldblatt, P., (...), De Angelis, D. 2021. Methods for modelling excess mortality across England during the COVID-19 pandemic, (2021) Statistical Methods in Medical Research, http://biblioproxy.cnr.it:2853/archive/doi: 10.1177/09622802211046384

Bontempi E., Coccia M., 2021. International trade as critical parameter of COVID-19 spread that outclasses demographic, economic, environmental, and pollution factors, Environmental Research, vol. 201, Article number 111514, PII S0013-9351(21)00808-2, https://doi.org/10.1016/j.envres.2021.111514.

Bontempi E., Coccia M., Vergalli S., Zanoletti A. 2021. Can commercial trade represent the main indicator of the COVID19 diffusion due to human-to-human interactions? A comparative analysis between Italy, France, and Spain, Environmental Research, vol. 201, Article number 111529, https://doi.org/10.1016/j.envres.2021.111529

Caliskan B., Nihan Özengin, S. Sıddık Cindoruk 2020. Air quality level, emission sources and control strategies in Bursa/Turkey. Atmospheric Pollution Research, In press, https://doi.org/10.1016/j.apr.2020.05.016

Coccia M. 2003. Metrics of R\&D performance and management of public research institute, Proceedings of IEEE- IEMC 03, Piscataway, pp. 231-236 - ISBN: 0-7803-8150-5

Coccia M. 2005. A taxonomy of public research bodies: a systemic approach, Prometheus, vol. 23, n. 1, pp. 6382. https://doi.org/10.1080/0810902042000331322

Coccia M. 2005a. Countrymetrics: valutazione della performance economica e tecnologica dei paesi e posizionamento dell'Italia, Rivista Internazionale di Scienze Sociali, vol. CXIII, n. 3, pp. 377-412. Stable URL: http://www.jstor.org/stable/41624216.

Coccia M. 2008. Measuring scientific performance of public research units for strategic change. Journal of Informetrics, vol. 2, n. 3, pp. 183-194. https://doi.org/10.1016/j.joi.2008.04.001

Coccia M. 2013. Population and technological innovation: the optimal interaction across modern countries, Working Paper Ceris del Consiglio Nazionale delle Ricerche, vol. 15, n. 7 - ISSN (Print): 1591-0709. Available at: http://viXra.org/abs/1803.0018

Coccia M. 2014. Steel market and global trends of leading geo-economic players. International Journal of trade and global markets, vol. 7, n.1, pp. 36-52, http://dx.doi.org/10.1504/IJTGM.2014.058714

Coccia M. 2015. Spatial relation between geo-climate zones and technological outputs to explain the evolution of technology. Int. J. Transitions and Innovation Systems, vol. 4, nos. 1-2, pp. 5-

21, http://dx.doi.org/10.1504/IJTIS.2015.074642.

Coccia M. 2016. Problem-driven innovations in drug discovery: co-evolution of the patterns of radical innovation with the evolution of problems, Health Policy and Technology, vol. 5, n. 2, pp. 143-

155. https://doi.org/10.1016/j.hlpt.2016.02.003

Page 12/20 
Coccia M. 2017. Varieties of capitalism's theory of innovation and a conceptual integration with leadership-oriented executives: the relation between typologies of executive, technological and socioeconomic performances. Int. J. Public Sector Performance Management, Vol. 3, No. 2, pp. 148-168. https://doi.org/10.1504/IJPSPM.2017.084672

Coccia M. 2017a. Disruptive firms and industrial change, Journal of Economic and Social Thought, vol. 4, n. 4, pp. 437450, http://dx.doi.org/10.1453/jest.v4i4.1511

Coccia M. 2017b. New directions in measurement of economic growth, development and under development, Journal of Economics and Political Economy, vol. 4, n. 4, pp. 382-395, http://dx.doi.org/10.1453/jepe.v4i4.1533

Coccia M. 2017c. Sources of disruptive technologies for industrial change. L'industria - rivista di economia e politica industriale, vol. 38, n. 1, pp. 97-120, DOI: 10.1430/87140

Coccia M. 2017d. Sources of technological innovation: Radical and incremental innovation problem-driven to support competitive advantage of firms. Technology Analysis \& Strategic Management, vol. 29, n. 9, pp. 1048-

1061, https://doi.org/10.1080/09537325.2016.1268682

Coccia M. 2017e. General Causes of Violent Crime: The Income Inequality, Working Paper CocciaLab n. 5, Available at SSRN eLibrary: https://ssrn.com/abstract=2951294, DOI: 10.13140/RG.2.2.36667.21285

Coccia M. 2018. An introduction to the methods of inquiry in social sciences, Journal of Social and Administrative Sciences, vol. 5, n. 2, pp. 116-126, http://dx.doi.org/10.1453/jsas.v5i2.1651

Coccia M. 2018a. An introduction to the theories of institutional change, Journal of Economics Library, vol. 5, n. 4, pp. 337-344, http://dx.doi.org/10.1453/jel.v5i4.1788

Coccia M. 2018b. General properties of the evolution of research fields: a scientometric study of human microbiome, evolutionary robotics and astrobiology, Scientometrics, vol. 117, n. 2, pp. 1265-1283, https://doi.org/10.1007/s11192018-2902-8

Coccia M. 2018c. The origins of the economics of Innovation, Journal of Economic and Social Thought, vol. 5, n. 1, pp. 9-28, http://dx.doi.org/10.1453/jest.v5i1.1574

Coccia M. 2018d. The relation between terrorism and high population growth, Journal of Economics and Political Economy, vol. 5, n. 1, pp. 84-104, http://dx.doi.org/10.1453/jepe.v5i1.1575

Coccia M. 2018e. Classification of innovation considering technological interaction, Journal of Economics Bibliography, vol. 5, n. 2, pp. 76-93, , http://dx.doi.org/10.1453/jeb.v5i2.1650.

Coccia M. 2018f. An introduction to the theories of national and regional economic development, Turkish Economic Review, vol. 5, n. 4, pp. 350-358, http://dx.doi.org/10.1453/ter.v5i4.1794.

Coccia M. 2019. Metabolism of public organizations: A case study, Journal of Social and Administrative Sciences, vol. 6, no. 1, pp. 1-9, http://dx.doi.org/10.1453/jsas.v6i1.1793

Coccia M. 2019a. The theory of technological parasitism for the measurement of the evolution of technology and technological forecasting, Technological Forecasting and Social Change, vol. 141, pp. 289-

304, https://doi.org/10.1016/j.techfore.2018.12.012

Page $13 / 20$ 
Coccia M. 2019b. A Theory of classification and evolution of technologies within a Generalized Darwinism, Technology Analysis \& Strategic Management, vol. 31, n. 5, pp. 517-531, http://dx.doi.org/10.1080/09537325.2018.1523385

Coccia M. 2019c. Theories of Development. A. Farazmand (ed.), Global Encyclopedia of Public Administration, Public Policy, and Governance, Springer Nature, https://doi.org/10.1007/978-3-319-31816-5_939-1

Coccia M. 2019d. The Role of Superpowers in Conflict Development and Resolutions. A. Farazmand (ed.), Global Encyclopedia of Public Administration, Public Policy, and Governance, Springer Nature Switzerland AG, https://doi.org/10.1007/978-3-319-31816-5_3709-1

Coccia M. 2019e. Theories of Self-determination. A. Farazmand (ed.), Global Encyclopedia of Public Administration, Public Policy, and Governance, Springer Nature Switzerland AG, https://doi.org/10.1007/978-3-319-31816-5_3710-1.

Coccia M. 2019f. Why do nations produce science advances and new technology? Technology in society, vol. 59, November, 101124, pp. 1-9, https://doi.org/10.1016/j.techsoc.2019.03.007

Coccia M. 2019g. Comparative Incentive Systems. A. Farazmand (ed.), Global Encyclopedia of Public Administration, Public Policy, and Governance, Springer Nature Switzerland AG, https://doi.org/10.1007/978-3-319-31816-5_3706-1

Coccia M. 2019h. Comparative World-Systems Theories. A. Farazmand (ed.), Global Encyclopedia of Public Administration, Public Policy, and Governance, Springer Nature Switzerland AG, https://doi.org/10.1007/978-3-31931816-5_3705-1

Coccia M. 2019i. Artificial intelligence technology in oncology: a new technological paradigm. ArXiv.org e-Print archive, Cornell University, USA. Permanent arXiv available at http://arxiv.org/abs/1905.06871

Coccia M. 2020. The impact of lockdown on public health during the first wave of covid-19 pandemic: lessons learned for designing effective containment measures to cope with second wave. CocciaLab Working Paper 2020 - No.

56B/2020 - National Research Council of Italy. Available on

medRxiv: https://medrxiv.org/cgi/content/short/2020.10.22.20217695v1, doi:

https://doi.org/10.1101/2020.10.22.20217695 Preprint 10.1101/2020.10.22.20217695

Coccia M. 2020a. Factors determining the diffusion of COVID-19 and suggested strategy to prevent future accelerated viral infectivity similar to COVID. Science of The Total Environment, vol. 729,

n.138474, https://doi.org/10.1016/j.scitotenv.2020.138474.

Coccia M. 2020b. How (Un)sustainable Environments are Related to the Diffusion of COVID-19: The Relation between Coronavirus Disease 2019, Air Pollution, Wind Resource and Energy. Sustainability, 12, 9709; doi:10.3390/su12229709

Coccia M. 2020c. How do environmental, demographic, and geographical factors influence the spread of COVID-19. Journal of Social and Administrative Sciences, vol. 7, no. 3, pp. 169-209. http://dx.doi.org/10.1453/jsas.v7i3.2018

Coccia M. 2020d. Destructive Technologies for Industrial and Corporate Change. In: Farazmand A. (eds), Global Encyclopedia of Public Administration, Public Policy, and Governance. Springer, Cham, https://doi.org/10.1007/978-3319-31816-5_3972-1

Coccia M. 2020e. Deep learning technology for improving cancer care in society: New directions in cancer imaging driven by artificial intelligence. Technology in Society, vol. 60, pp. 1-11, art. n.

101198, https://doi.org/10.1016/j.techsoc.2019.101198

Page $14 / 20$ 
Coccia M. 2020f. How does science advance? Theories of the evolution of science. Journal of Economic and Social Thought, vol. 7, n. 3, pp. 153-180. http://dx.doi.org/10.1453/jest.v7i3.2111

Coccia M. 2020g. The evolution of scientific disciplines in applied sciences: dynamics and empirical properties of experimental physics, Scientometrics, n. 124, pp. 451-487. https://doi.org/10.1007/s11192-020-03464-y

Coccia M. 2020h. Multiple working hypotheses for technology analysis, Journal of Economics Bibliography, vol. 7., n. 2, pp. 111-126, http://dx.doi.org/10.1453/jeb.v7i2.2050

Coccia M. 2020i. Asymmetry of the technological cycle of disruptive innovations. Technology Analysis \& Strategic Management, vol. 32, n. 12, p. 1462-1477. https://doi.org/10.1080/09537325.2020.1785415

Coccia M. 2020I. An index to quantify environmental risk of exposure to future epidemics of the COVID-19 and similar viral agents: Theory and Practice. Environmental Research, volume 191, December, Article number 110155. https://doi.org/10.1016/j.envres.2020.110155

Coccia M. 2021. Effects of the spread of COVID-19 on public health of polluted cities: results of the first wave for explaining the dejà vu in the second wave of COVID-19 pandemic and epidemics of future vital agents. Environmental Science and Pollution Research. 28(15), 19147-19154. https://doi.org/10.1007/s11356-020-11662-7

Coccia M. 2021a. The effects of atmospheric stability with low wind speed and of air pollution on the accelerated transmission dynamics of COVID-19. International Journal of Environmental Studies, vol. 78, n. 1, pp. 127, https://doi.org/10.1080/00207233.2020.1802937

Coccia M. 2021b. Pandemic Prevention: Lessons from COVID-19. Encyclopedia 2021, 1, 433-444. MDPI, Basel, Switzerland, Encyclopedia of COVID-19, open access journal, https://doi.org/10.3390/encyclopedia1020036

Coccia M. 2021c. Comparative Critical Decisions in Management. In: Farazmand A. (eds), Global Encyclopedia of Public Administration, Public Policy, and Governance. Springer Nature Switzerland AG 2020, Springer, Cham. https://doi.org/10.1007/978-3-319-31816-5_3969-1

Coccia M. 2021d. The impact of first and second wave of the COVID-19 pandemic: comparative analysis to support control measures to cope with negative effects of future infectious diseases in society. Environmental Research, vol. 197, June, Article number 111099, PII S0013-9351(21)00393-5, https://doi.org/10.1016/j.envres.2021.111099

Coccia M. 2021e. High health expenditures and low exposure of population to air pollution as critical factors that can reduce fatality rate in COVID-19 pandemic crisis: a global analysis Environmental Research, vol. 199, Article number 111339, https://doi.org/10.1016/j.envres.2021.111339

Coccia M. 2021f. How do low wind speeds and high levels of air pollution support the spread of COVID19? Atmospheric Pollution Research, vol. 12, n.1, pp. 437-445., https://doi.org/10.1016/j.apr.2020.10.002.

Coccia M. 2021g. The relation between length of lockdown, numbers of infected people and deaths of COVID-19, and economic growth of countries: Lessons learned to cope with future pandemics similar to Covid-19. Science of The Total Environment, n. 145801. https://doi.org/10.1016/j.scitotenv.2021.145801

Coccia M. 2021h. How a Good Governance of Institutions Can Reduce Poverty and Inequality in Society? In Nezameddin Faghih, Ali Hussein Samadi (Editor) Legal-Economic Institutions, Entrepreneurship, and Management, 
Perspectives on the Dynamics of Institutional Change from Emerging Markets, Springer Nature D0I 978-3-030-609788_4, (eBook) https://doi.org/10.1007/978-3-030-60978-8, pp. 65-94

Coccia M. 2021i. Effects of human progress driven by technological change on physical and mental health, STUDI DI SOCIOLOGIA, 2021, N. 2, pp. 113-132, https://doi.org/10.26350/000309_000116

Coccia M. 2021l. Evolution of technology in replacement of heart valves: Transcatheter aortic valves, a revolution for management of valvular heart diseases, Health Policy and Technology, vol. 10, n. 2, Article number 100512, , https://doi.org/10.1016/j.hlpt.2021.100512

Coccia M. 2022. The spread of the novel Coronavirus disease 2019 in polluted cities: Lessons learned from environmental and demographic factors for prevention of pandemic diseases. In Editors: Faghih, Nezameddin, Forouharfar, Amir (Eds.)Socioeconomic Dynamics of the COVID-19 Crisis, Global, Regional, and Local Perspectives, Springer International Publishing, DOI: 10.1007/978-3-030-89996-7

Coccia M. 2022a. Preparedness of countries to face covid-19 pandemic crisis: Strategic positioning and underlying structural factors to support strategies of prevention of pandemic threats, Environmental Research, Volume 203, n. 111678, https://doi.org/10.1016/j.envres.2021.111678.

Coccia M. 2022b. COVID-19 pandemic over 2020 (with lockdowns) and 2021 (with vaccinations): similar effects for seasonality and environmental factors. Environmental Research, Volume 208, 15 May 2022, n.

112711. https://doi.org/10.1016/j.envres.2022.112711

Coccia M. 2022c. Optimal levels of vaccination to reduce COVID-19 infected individuals and deaths: A global analysis. Environmental Research, vol. 204, Part C, March 2022, Article number

112314, https://doi.org/10.1016/j.envres.2021.112314

Coccia M. 2022d. Probability of discoveries between research fields to explain scientific and technological change. Technology in Society, vol. 68, February, n. 101874, https://doi.org/10.1016/j.techsoc.2022.101874

Coccia M., Bellitto M. 2018. Human progress and its socioeconomic effects in society, Journal of Economic and Social Thought, vol. 5, n. 2, pp. 160-178, http://dx.doi.org/10.1453/jest.v5i2.1649

Coccia M., Benati I. 2018. Rewards in public administration: A proposed classification, Journal of Social and Administrative Sciences, vol. 5, n. 2, pp. 68-80, http://dx.doi.org/10.1453/jsas.v5i2.1648.

Coccia M., Cadario E. 2014. Organisational (un)learning of public research labs in turbulent context. International Journal of Innovation and Learning, vol. 15, n. 2, pp.115-129, https://doi.org/10.1504/IJIL.2014.059756

Coccia M., Finardi U. 2012. Emerging nanotechnological research for future pathway of biomedicine. International Journal of Biomedical nanoscience and nanotechnology, vol. 2, nos. 3-4, pp. 299-317.

DOI: 10.1504/IJBNN.2012.051223

Coccia M., Finardi U. 2013. New technological trajectories of non-thermal plasma technology in medicine. Int. J. Biomedical Engineering and Technology, vol. 11, n. 4, pp. 337-356, DOI: 10.1504/IJBET.2013.055665

Coccia M., Rolfo S. 2000. Ricerca pubblica e trasferimento tecnologico: il caso della regione Piemonte in Rolfo S. (eds) Innovazione e piccole imprese in Piemonte, Franco Angeli Editore, Milano (Italy), ISBN: 9788846418784 
Coccia M., Rolfo S. 2008. Strategic change of public research units in their scientific activity, Technovation, vol. 28, n. 8, pp. 485-494. https://doi.org/10.1016/j.technovation.2008.02.005

Coccia M., Watts J. 2020. A theory of the evolution of technology: technological parasitism and the implications for innovation management, Journal of Engineering and Technology Management, vol. 55 (2020) 101552, https://doi.org/10.1016/j.jengtecman.2019.11.003

Copat C., Cristaldi A., Fiore M., (...), Conti G.O., Ferrante M. 2020. The role of air pollution (PM and NO 2 ) in COVID-19 spread and lethality: A systematic review . Environmental Research, 191,110129

Davies, N.G., Jarvis, C.I., van Zandvoort, K., Clifford, S., Sun, F.Y., Funk, S., Medley, G., (...), Keogh, R.H. 2021. Increased mortality in community-tested cases of SARS-CoV-2 lineage B.1.1.7 (2021) Nature, 593 (7858), pp. 270-274.

de Vlas, S. J., Coffeng, L. E. 2021. Achieving herd immunity against COVID-19 at the country level by the exit strategy of a phased lift of control. Scientific reports, 11(1), 4445. https://doi.org/10.1038/s41598-021-83492-7

Fontanet, A., Autran, B., Lina, B., Kieny, M.P., Karim, S.S.A., Sridhar, D. 2021. SARS-CoV-2 variants and ending the COVID19 pandemic ((2021) The Lancet, 397 (10278), pp. 952-954.

Garber, A.M. 2021. Learning from Excess Pandemic Deaths (Open Access)(2021) JAMA - Journal of the American Medical Association, 325 (17), pp. 1729-1730.

IMARC 2022. Mechanical Ventilators Market: Global Industry Trends, Share, Size, Growth, Opportunity and Forecast 2021-2026, https://www.imarcgroup.com/mechanical-ventilators-market (accessed 2022)

Islam, N., Shkolnikov, V. M., Acosta, R. J., Klimkin, I., Kawachi, I., Irizarry, R. A., Alicandro, G., Khunti, K., Yates, T., Jdanov, D. A., White, M., Lewington, S., \& Lacey, B. (2021). Excess deaths associated with covid-19 pandemic in 2020: age and sex disaggregated time series analysis in 29 high income countries. BMJ (Clinical research ed.), 373, n1137.

https://doi.org/10.1136/bmj.n1137

Johns Hopkins Center for System Science and Engineering, 2022. Coronavirus COVID-19 Global

Cases, https://gisanddata.maps.arcgis.com/apps/opsdashboard/index.html\#/bda7594740fd40299423467b48e9ecf6 (accessed in 14 January 2022).

Kapitsinis N. 2020. The underlying factors of the COVID-19 spatially uneven spread. Initial evidence from regions in nine EU countries. Regional Science Policy and Practice, 12(6), pp. 1027-1045

Kiang, M.V., Irizarry, R.A., Buckee, C.O., Balsari, S. 2020. Every body counts: Measuring mortality from the COVID-19 pandemic (Open Access)(2020) Annals of Internal Medicine, 173 (12), pp. 1004-1007.

https://www.acpjournals.org/doi/10.7326/M20-3100,doi: 10.7326/M20-3100

Lau H., Khosrawipour T., Kocbach P., Ichii H., Bania J., Khosrawipour V. 2021. Evaluating the massive underreporting and undertesting of COVID-19 cases in multiple global epicenters. Pulmonology, 27(2), 110-115.

https://doi.org/10.1016/j.pulmoe.2020.05.015

Liu Z., Magal P., Webb G. 2021. Predicting the number of reported and unreported cases for the COVID-19 epidemics in China, South Korea, Italy, France, Germany and United Kingdom. Journal of theoretical biology, 509, 110501. https://doi.org/10.1016/j.jtbi.2020.110501 
Mayo Clinic 2021. Different types of COVID-19 vaccines: How they work. https://www.mayoclinic.org/diseasesconditions/coronavirus/in-depth/different-types-of-covid-19-vaccines/art-20506465 (accessed 6 September 2021).

Mayo Clinic 2022. COVID-19 variants: What's the concern?, https://www.mayoclinic.org/diseasesconditions/coronavirus/expert-answers/covid-variant/faq-20505779 (accessed January 2022)

Moore, S., Hill, E.M., Tildesley, M.J., Dyson, L., Keeling, M.J. 2021. Vaccination and non-pharmaceutical interventions for COVID-19: a mathematical modelling study ((2021) The Lancet Infectious Diseases, 21 (6), pp. 793-802

Nicastro, F., Sironi, G., Antonello, E., (...), Trabattoni, D., Clerici, M. 2021. Solar UV-B/A radiation is highly effective in inactivating SARS-CoV-2, Scientific Reports 11(1),14805

Our World in Data 2022. Coronavirus (COVID-19) Vaccinations - Statistics and Research - Our World in Data https://ourworldindata.org/covid-vaccinations (Accessed 25 January 2022).

Our World in Data 2022a. Number of medical ventilators, 2020. https://ourworldindata.org/grapher/number-ofmedical-ventilators (accessed January 2022)

Pagliaro M., Coccia M. 2021. How self-determination of scholars outclasses shrinking public research lab budgets, supporting scientific production: a case study and R\&D management implications. Heliyon. vol. 7, n. 1, e05998. https://doi.org/10.1016/j.heliyon.2021.e05998

Papanikolaou, V., Chrysovergis, A., Ragos, V., Tsiambas, E., Katsinis, S., Manoli, A., Papouliakos, S., Roukas, D., Mastronikolis, S., Peschos, D., Batistatou, A., Kyrodimos, E., Mastronikolis, N. 2022. From delta to Omicron: S1-RBD/S2 mutation/deletion equilibrium in SARS-CoV-2 defined variants. Gene, 814, 146134. Advance online publication. https://doi.org/10.1016/j.gene.2021.146134

Prieto Curiel, R., González Ramírez, H. 2021. Vaccination strategies against COVID-19 and the diffusion of antivaccination views, Scientific Reports 11(1),6626

Pronti A., Coccia M. 2020. Multicriteria analysis of the sustainability performance between agroecological and conventional coffee farms in the East Region of Minas Gerais (Brazil). Renewable Agriculture and Food Systems, vol. 36, n. 3, pp. 299-306. https://doi.org/10.1017/S1742170520000332

Randolph H. E., Barreiro L. B. 2020. Herd immunity: understanding COVID-19. Immunity 52, 737-741

Ritchie H., Ortiz-Ospina E., Beltekian D., Mathieu E., Hasel J., Macdonald B., Giattino C., Roser, M. 2020. Policy Responses to the Coronavirus Pandemic. Our World in Data, Statistics and Research. Retrieved July 7, 2020, from https://ourworldindata.org/policy-responses-covid

Rosario Denes K.A., Mutz Yhan S., Bernardes Patricia C., Conte-Junior Carlos A., 2020. Relationship between COVID-19 and weather: Case study in a tropical country. International Journal of Hygiene and Environmental Health 229, 113587

Saadi, N., Chi, Y.-L., Ghosh, S., (...), Jit, M., Vassall, A. $\quad$ 2021. Models of COVID-19 vaccine prioritisation: a systematic literature search and narrative review, BMC Medicine19(1),318

Sanmarchi, F., Golinelli, D., Lenzi, J., Esposito, F., Capodici, A., Reno, C., Gibertoni, D. 2021. Exploring the Gap between Excess Mortality and COVID-19 Deaths in 67 Countries (Open Access)(2021) JAMA Network Open, 4 (7), art. no. e2117359. 
Seligman B, Ferranna M, Bloom DE 2021. Social determinants of mortality fromCOVID-19: A simulation study using NHANES.PLoS Med 18(1): e1003490. https://doi.org/10.1371/journal.pmed.1003490

Shattock, A.J., Le Rutte, E.A., Dünner, R.P., (...), Chitnis, N., Penny, M.A. 2022. Impact of vaccination and nonpharmaceutical interventions on SARS-CoV-2 dynamics in Switzerland, Epidemics38,100535

Soo Hoo G. W. 2010. Noninvasive ventilation in adults with acute respiratory distress: a primer for the clinician. Hospital practice (1995), 38(1), 16-25. https://doi.org/10.3810/hp.2010.02.275

Soo Hoo G. W. 2020. Noninvasive ventilation. Medscape. https://emedicine.medscape.com/article/304235-overview (Accessed January 2021)

Stokes, A. C., Lundberg, D. J., Bor, J., Bibbins-Domingo, K. 2021. Excess Deaths During the COVID-19 Pandemic: Implications for US Death Investigation Systems. American journal of public health, 111(S2), S53-S54. https://doi.org/10.2105/AJPH.2021.306331

Stokes, A.C., Lundberg, D.J., Elo, I.T., Hempstead, K., Bor, J., Preston, S.H. 2021a. COVID-19 and excess mortality in the United States: A county-level analysis (Open Access) (2021) PLoS Medicine, 18 (5), art. no. e1003571

The World Bank 2022. GDP per capita (constant 2015 US\$), World Bank national accounts data, and OECD National Accounts data files. https://data.worldbank.org/indicator/NY.GDP.PCAP.KD (Accessed January 2022).

The World Bank 2022a. Data, Population, total. https://data.worldbank.org/indicator/SP.POP.TOTL (Accessed January 2022).

Vinceti, M., Filippini, T., Rothman, K. J., Di Federico, S., \& Orsini, N. 2021. SARS-CoV-2 infection incidence during the first and second COVID-19 waves in Italy. Environmental research, 197,

111097. https://doi.org/10.1016/j.envres.2021.111097

Woolf, S.H., Chapman, D.A., Sabo, R.T., Zimmerman, E.B. 2021. Excess Deaths from COVID-19 and Other Causes in the US, March 1, 2020, to January 2, 2021 (Open Access) (2021) JAMA - Journal of the American Medical Association, 325 (17), pp. 1786-1789.

\section{Figures}




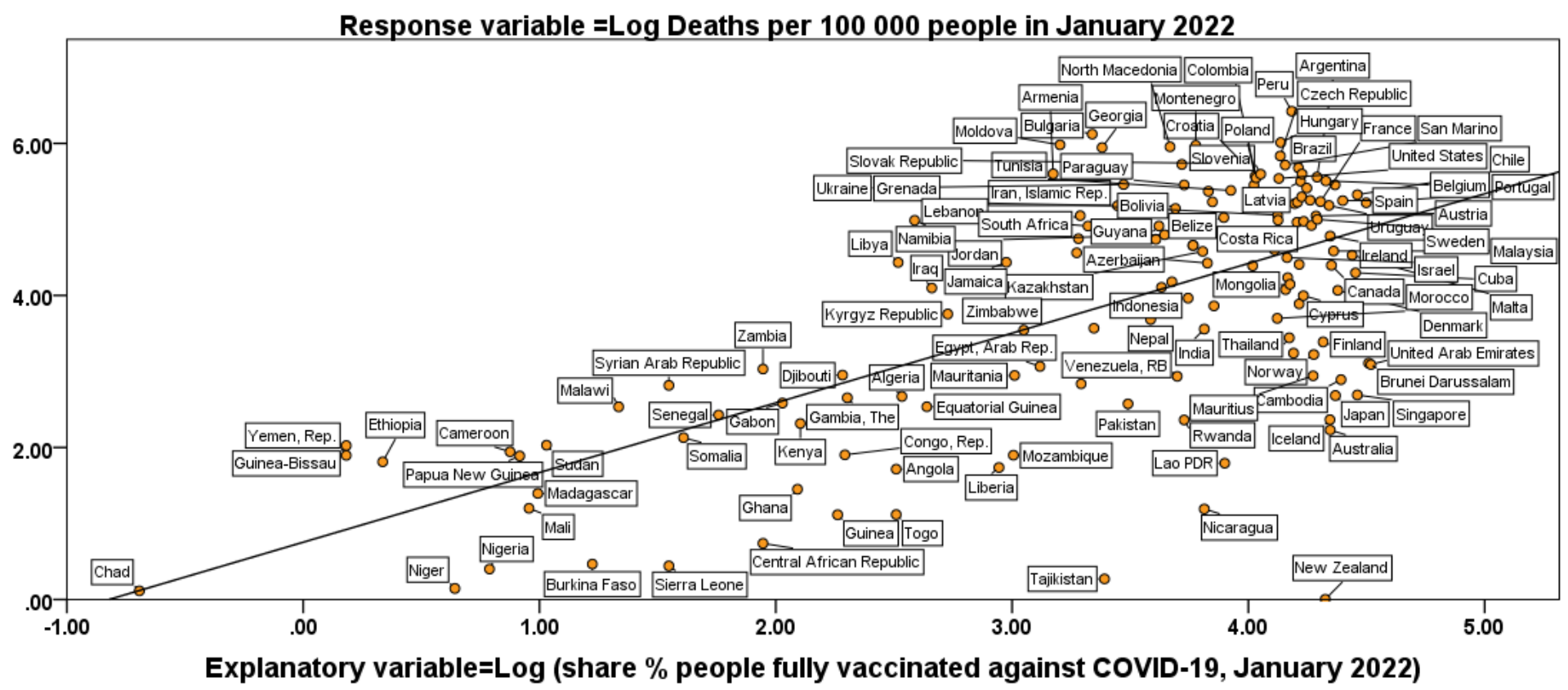

Figure 1

Relation of COVID-19 deaths per 100000 people on share of people vaccinated against COVID-19 (\%) based on log$\log$ model.

\begin{tabular}{l|l} 
& $\begin{array}{l}\text { - High air pollution and exposure of population to days exceeding levels of } \mathrm{PM}_{2.5} \\
\text { air pollution (e.g., max } 50 \text { days of high levels of air pollution per year) }\end{array}$ \\
$\begin{array}{l}\text { Factors determining high } \\
\text { mortality rates, though a } \\
\text { high share of vaccinated } \\
\text { people (factors to be } \\
\begin{array}{l}\text { considered when shaping } \\
\text { general strategies to } \\
\text { mitigate case fatality rates } \\
\text { of future waves of COVID- } \\
19 \text { and similar pandemics) }\end{array}\end{array}$ & $\begin{array}{l}\text { - Low wind speed, low temperature and high atmospheric humidity } \\
\text { - Lew SARS-CoV-2 variants of concern (e.g., Delta, etc.) }\end{array}$ \\
- Low health expenditure as \% of GDP
\end{tabular}

Figure 2

Factors determining high mortality rates, though a high share of vaccinated people between countries. Factors to be considered to design general guidelines to constrain pandemic crises of novel viral agents like Severe Acute Respiratory Syndrome Coronavirus 2 (SARS-CoV-2). 